\title{
PENGARUH METODE PENGERINGAN DENGAN TEMPERATUR RUANG DAN MICROWAVE TERHADAP KEKUATAN KOMPRESI DAN PERUBAHAN DIMENSI GIPS TIPE IV MODEL KERJA GIGI TIRUAN
}

\author{
Dwi Tjahyaning Putranti*, Yosanna Hayati Sitorus ${ }^{* * *}$ \\ *Departemen Prostodonsia Fakultas Kedokteran Gigi Universitas Sumatera Utara, \\ **Mahasiswa Fakultas Kedokteran Gigi Universitas Sumatera Utara \\ Email: yhsitorus19@gmail.com
}

\begin{abstract}
Abstrak
Bahan yang umum digunakan dalam proses pembuatan gigi tiruan adalah gips yang berasal dari kalsium sulfat dihidrat murni. Gips tipe IV merupakan gips yang digunakan sebagai bahan model kerja untuk proses pembuatan mahkota dan jembatan gigi tiruan. Model kerja gigi tiruan yang akurat harus memiliki kekuatan kompresi dan perubahan dimensi yang baik. Waktu yang menjadi pertimbangan dokter gigi dan tekniker dalam hal menunggu pengerasan model kerja sebelum melakukan prosedur laboratoris dapat diatasi dengan metode pengeringan alternatif yaitu pengeringan microwave. Tujuan penelitian ini adalah untuk mengetahui pengaruh metode pengeringan dengan temperatur ruang dan microwave terhadap kekuatan kompresi dan perubahan dimensi gips tipe IV sebagai model kerja gigi tiruan. Rancangan penelitian ini adalah eksperimental laboratoris. Sampel penelitian yang digunakan adalah gips tipe IV yang dikeringkan dengan temperatur ruang $23^{\circ} \pm 2^{\circ} \mathrm{C}$ selama 24 jam,microwave $600 \mathrm{~W}$ selama 5 menit dan 10 menit dengan ukuran sampel $20 \mathrm{~mm}$ x $40 \mathrm{~mm}$ untuk uji kekuatan kompresi dan $20 \mathrm{~mm}$ x $30 \mathrm{~mm}$ untuk uji perubahan dimensi. Jumlah sampel sebanyak 60 sampel yang terdiri dari 30 sampel untuk uji kekuatan kompresi dan 30 sampel untuk uji perubahan dimensi. Setiap sampel dilakukan uji kekuatan kompresi dan perubahan dimensi, kemudian dianalisis dengan uji ANOVAuntuk mengetahui pengaruh metode pengeringan temperatur ruang $23^{\circ} \pm 2^{\circ} \mathrm{C}$ selama 24 jam dengan microwave $600 \mathrm{~W}$ selama 5 menit dan 10 menit terhadap kekuatan kompresi dan perubahan dimensi gips tipe IV sebagai model kerja gigi tiruan, kemudian dilanjutkan dengan uji LSD untuk melihat perbedaan pengaruh antara masing-masing kelompok. Hasil penelitian menunjukkan bahwa metode pengeringan microwave $600 \mathrm{~W}$ selama 5 menit dapat menjadi metode pengeringan alternatif untuk meningkatkan kekuatan kompresi dengan perubahan dimensi yang rendah.
\end{abstract}

Kata kunci : Gips, microwave, kekuatan kompresi, perubahan dimensi

\section{PENDAHULUAN}

Salah satu bahan pembuatan model gigi tiruan adalah gips yang berasal dari alam dan mulai digunakan di kedokteran gigi sejak tahun $1756 .{ }^{1}$ Bahan gips yang digunakan dalam kedokteran gigi berasal dari kalsium sulfat dihidrat murni $\left(\mathrm{CaSO}_{4}-2 \mathrm{H}_{2} \mathrm{O}\right)$ yang dipanaskan dengan temperatur yang tinggi sehingga terbentuk kalsium sulfat hemihidrat $\left(\mathrm{CaSO}_{4}\right)_{2} \mathrm{H}_{2} \mathrm{O}{ }^{2}$ Menurut Spesifikasi ADA No. 25 terdapat 5 jenis gips yaitu: impression plaster (tipe I), model plaster (tipe II), dental stone (tipe III), dental stone high strength (tipe IV)dan dental stone high strength-high expansion (tipe V).Perbedaan jenis gips tersebut berdasarkan pada penggunaan serta sifat-sifat bahan gips.Gips tipe IV secara luas dapat digunakan untuk pembuatan model kerja sebagai media pembuatan gigi tiruan, yaitu pembuatan mahkota dan jembatan gigi tiruan. $^{3}$
Karakteristik pada bahan gips untuk pembuatan model kerja yaitu meliputi: setting time, kekerasan permukaan dan ketahanan terhadap abrasi, kekuatan kompresi, setting ekspansi, dan perubahan dimensi. Model kerja pada pembuatan mahkota dan jembatan gigi tiruan harus memiliki kekuatan kompresi dan ketahanan terhadap abrasi yang baik, karena pada proses pembuatan pola malam pada dai yang akan diukir dengan menggunakan instrumen tajam. ${ }^{4}$ Kekuatan kompresi adalah kemampuan material untuk menahan fraktur dan merupakan faktor penting dalam menentukan kekerasan permukaan dan ketahanan terhadap abrasi dari bahan gips.Berdasarkan spesifikasi ADA No.25 gips tipe IV memiliki kekuatan kompresi minimal yaitu sebesar 34,5 $\mathrm{MPa}^{3}$ Perubahan dimensi juga sangat penting karena model kerja harus mereproduksi struktur intraoral secara akurat dan harus tetap pada dimensi yang sama.Perubahan dimensi biasanya dinyatakan sebagai persentase dari besar atau volume. ${ }^{1}$ Berdasarkan spesifikasi ADA No. 25 setting 
ekspansi gips tipe IV adalah 0,00-0,10\%. ${ }^{3}$ Secara umum, beberapa faktor yang memengaruhi kekuatan kompresi dan perubahan dimensi gips antara lain: rasio air dengan bubuk, waktu dan kecepatan pengadukan, akselerator dan retarder, temperatur dan kelembaban udara. ${ }^{4}$ Temperatur dan kelembaban udara yang memengaruhi kekuatan kompresi dan perubahan dimensi yaitu pada metode pengeringan dengan temperatur ruang dan microwave.Model kerja gigi tiruan yang masih mengandung air biasanya memiliki kekuatan yang cukup memadai. Normalnya waktu untuk menunggu model kerja mengeras adalah selama 24-48 jam sebelum memulai prosedur laboratorium.Waktu merupakan salah satu pertimbangan bagi para tekniker di laboratorium dan dokter gigi dalam hal mempersingkat waktu untuk menunggu model kerja mengeras sebelum memanipulasi model kerja tersebut, ${ }^{5,6}$

Teknik pengeringan dengan microwave menjadi metode yang efisien dan akurat dari beberapa jenis pengeringan bahan gips dengan teknik yang berbeda. ${ }^{7}$ Pengeringan dengan microwave dapat mempersingkat waktu kerja dan meningkatkan kekuatan kompresi pada model kerja. Microwave merupakan konversi energi listrik menjadi panas endotermik dengan waktu yang relatif lebih singkat dan bukan merupakan pemanasan konduksi seperti pengeringan dengan oven konvensional. ${ }^{6} \mathrm{Hal}$ ini terjadi karena microwave merupakan alat yang dapat menghasilkan gelombang elektromagnetik, yang diperoleh dari generator yang disebut sebagai magnetron. Pemanasan microwave disebut sebagai pemanasan dielektrik karena adanya polarisasi dipolar. Getaran molekul dapat menghasilkan panas dan apabila gelombang mikro mengenai cairan maka energi gelombang mikro tersebut akan diserap oleh cairan pada gips tersebut, sehingga gips dapat mengering secara merata dengan waktu yang singkat. ${ }^{8}$ Hasan (2008) tidak merekomendasikan pengeringan bahan gips dalam microwave dengan tingkat daya tinggi sebesar $1450 \mathrm{~W}$ untuk meningkatkan kekuatan kompresi bahan gips, karena dapat menyebabkan lubang atau porositas dan retakan pada permukaan luar yang dapat menyebabkan fraktur selama pemakaian. ${ }^{6}$

\section{BAHAN DAN METODE}

Penelitian ini merupakan penelitian eksperimental laboratorium dengan desain penelitian post test only control group.Sampel dibuat dari gips tipe IV yang dikeringkan setelah pengadukan dengan temperatur ruang $23^{\circ} \pm 2^{\circ} \mathrm{C}$ selama 24 jam dan microwave $600 \mathrm{~W}$ selama 5 menit dan 10 menit. Sampel dibuat dengan model induk dari stainless steeldengan ukurandiameter 20 $\mathrm{mm} \times$ tinggi $40 \mathrm{~mm}$ untuk uji kekuatan kompresi, dan dengan ukuran diameter $20 \mathrm{~mm} x$ tinggi 30 mmuntuk uji perubahan dimensi. Jumlah sampel keseluruhan adalah 60 sampel, terdiri dari 30 sampel untuk uji kekuatan kompresi dan 30 sampel untuk uji perubahan dimensi. Bubuk 100 grdengan air25 ml diaduk mengunakan spatula selama 60 detik hingga homogen. Adonan gips yang telah diaduk dituang ke dalam tabung silinder stainless steel yang beralaskan glass slab sambil digetarkan diatas vibrator selama beberapa detik sampai penuh. Adonan yang berlebih diratakan dengan glass slab yang diletakkan di atas master mold dan ditekan sampai menyentuh permukaan atas. Sampel gips dikeluarkan dari master mold setelah 30 menit dari waktu awal pengadukan dan dibiarkan mengeras sepenuhnya pada temperatur ruang $23^{\circ} \pm 2^{\circ} \mathrm{C}$ selama 24 jam (kelompok A), dan dikeringkan dalam microwave $600 \mathrm{~W}$ selama 5 menit (kelompok B) dan microwave $600 \mathrm{~W}$ selama 10 menit (kelompok C).

Pengujian kekutan kompresi dilakukan dengan menggunakan alat Universal Testing Machine dan pengujian perubahan dimensi dilakukan dengan alat Kaliper Digital dengan ketelitian 0,01 mm. Analisis data dilakukan dengan uji Univarian dan uji ANOVA, kemudian dilanjutkan dengan uji LSD.

\section{HASIL}

Nilai rerata kekuatan kompresi pada kelompok A adalah 35,6640 dan standar deviasi 0,5738. Nilai rerata kekuatan kompresi pada kelompok B adalah 37,3860 dan standar deviasi 0,7424. Nilai rerata kekuatan kompresi pada kelompok $\mathrm{C}$ adalah 42,0550 dan standar deviasi 1,5331 (Tabel 1).

Tabel 1. Nilai kekuatan kompresi gips tipe IV model kerja gigi tiruan pada metode pengeringan dengan temperatur ruang $23^{\circ} \pm 2^{\circ} \mathrm{C}$ selama 24 jam dan microwave $600 \mathrm{~W}$ selama 5 menit dan 10 menit

\begin{tabular}{|c|c|c|c|}
\hline \multirow[b]{2}{*}{$\begin{array}{c}\text { No. } \\
\text { Sampel }\end{array}$} & \multicolumn{3}{|c|}{$\begin{array}{c}\text { Kekuatan Kompresi Gips Tipe IV Model } \\
\text { Kerja Gigi Tiruan (MPa) }\end{array}$} \\
\hline & $\begin{array}{c}\text { Kelompok } \\
\text { A } \\
\text { (Temperatur } \\
\text { Ruang } \\
23^{\circ} \pm 2^{\circ} \text { Csela } \\
\text { ma } \\
24 \text { jam) }\end{array}$ & $\begin{array}{c}\text { Kelompok B } \\
\text { (Microwave } \\
600 \mathrm{~W} \\
\text { selama } \\
5 \text { menit) }\end{array}$ & $\begin{array}{c}\text { Kelompok C } \\
\text { (Microwave } \\
600 \mathrm{~W} \\
\text { selama } \\
10 \text { menit) }\end{array}$ \\
\hline 1 & 36,1407 & $38,3767^{* *}$ & 40,3426 \\
\hline 2 & 35,0910 & 36,6406 & $44,8572^{* * *}$ \\
\hline 3 & 35,9908 & $36,5520^{*}$ & 43,9189 \\
\hline 4 & 36,0408 & 37,7881 & 40,4397 \\
\hline 5 & 35,2410 & 36,6109 & 42,8177 \\
\hline 6 & $35,0410^{*}$ & 37,9058 & $40,3191^{*}$ \\
\hline 7 & $36,5349^{* * *}$ & 36,5520 & 42,0260 \\
\hline 8 & 36,2407 & 37,9058 & 42,1437 \\
\hline 9 & 35,2410 & 37,3172 & 42,4380 \\
\hline 10 & 35,0910 & 38,259 & 41,3197 \\
\hline & $\begin{array}{l}\bar{X}=35,6640 \\
\mathrm{SD}=0,5738\end{array}$ & $\begin{array}{l}\bar{X}=37,3860 \\
\mathrm{SD}=0,7424\end{array}$ & $\begin{array}{l}\bar{X}=42,0550 \\
\mathrm{SD}=1,5351\end{array}$ \\
\hline
\end{tabular}

Keterangan : * Nilai terkecil $* *$ Nilai terbesar

Hasil uji ANOVA satu arah menunjukkan bahwa adanyapengaruh yang signifikan pada metode pengeringan dengan temperatur ruang $23^{\circ} \pm 2^{\circ} \mathrm{C}$ selama 24 jam dan microwave $600 \mathrm{~W}$ selama 5 menit dan 10 menit terhadap kekuatan kompresi gips tipe IV dengan nilai $\mathrm{p}=0,0001(\mathrm{p}<0,05)($ Tabel 2). 
Tabel 2. Pengaruh metode pengeringan dengan temperatur ruang $23^{\circ} \pm 2^{\circ} \mathrm{C}$ selama 24 jam dan microwave $600 \mathrm{~W}$ selama 5 menit dan 10 menit terhadap kekuatan kompresi gips Tipe IV model kerja gigi tiruan

\begin{tabular}{|c|c|c|c|}
\hline \multirow[t]{2}{*}{ Kelompok } & \multicolumn{2}{|c|}{$\begin{array}{c}\text { Kekuatan Kompresi } \\
\text { Gips Tipe IV Model } \\
\text { Kerja Gigi Tiruan (MPa) }\end{array}$} & \multirow[t]{2}{*}{$\mathrm{p}$} \\
\hline & $\mathrm{n}$ & $\bar{X} \pm \mathrm{SD}$ & \\
\hline $\begin{array}{c}\text { A (Temperatur } \\
\text { Ruang } \\
23^{\circ} \pm 2^{\circ} \text { Cselam } \\
\text { a } 24 \text { jam) }\end{array}$ & 10 & $\begin{array}{c}35,6640 \pm \\
0,5738\end{array}$ & \multirow{3}{*}{$\mathrm{p}=0,0001^{*}$} \\
\hline $\begin{array}{l}\text { B (Microwave } \\
600 \mathrm{~W} \text { selama } \\
5 \text { menit) }\end{array}$ & 10 & $\begin{array}{c}37,3860 \pm \\
0,7424 \\
\end{array}$ & \\
\hline $\begin{array}{c}\text { C (Microwave } \\
600 \mathrm{~W} \text { selama } \\
10 \text { menit) }\end{array}$ & 10 & $\begin{array}{c}42,0550 \pm \\
1,5331\end{array}$ & \\
\hline
\end{tabular}

Keterangan : * Signifikan $(\mathrm{p}<0,05)$

Untuk mengetahui perbedaan pengaruh antara kelompok temperatur ruang $23^{\circ} \pm 2^{\circ} \mathrm{C}$ selama 24 jam (kelompok A) dengan microwave $600 \mathrm{~W}$ selama 5 menit (kelompok B) dan microwave $600 \mathrm{~W}$ selama 10 menit (kelompok C) terhadap kekuatan kompresi gips tipe IV model kerja gigi tiruan, dilakukan dengan uji LSD. Hasil uji LSD terdapat perbedaan kekuatan kompresi yang signifikan antara kelompok A dengan B, kelompok A dengan kelompok $\mathrm{C}$ dan kelompok $\mathrm{B}$ dengan kelompok $\mathrm{C}$ (Tabel 3).

Tabel 3. Perbedaan pengaruh metode pengeringan dengan temperatur ruang $23^{\circ} \pm 2^{\circ} \mathrm{C}$ selama 24 jam dan microwave $600 \mathrm{~W}$ selama 5 menit dan 10 menit terhadap kekuatan kompresi gips tipe IV model kerja gigi tiruan

\begin{tabular}{|c|c|c|c|}
\hline $\begin{array}{c}\text { Kelompok gips } \\
\text { tipe IV model } \\
\text { kerja gigi tiruan }\end{array}$ & $\begin{array}{c}\text { Temperatur } \\
\text { ruang } \\
23^{\circ} \pm 2^{\circ} \mathrm{Csela} \\
\text { ma } \\
24 \mathrm{jam}\end{array}$ & $\begin{array}{c}\text { Microwave } \\
600 \mathrm{~W} \\
\text { selama } \\
5 \text { menit }\end{array}$ & $\begin{array}{c}\text { Microwave } \\
600 \mathrm{~W} \\
\text { selama } \\
10 \text { menit }\end{array}$ \\
\hline $\begin{array}{c}\text { Temperatur } \\
\text { ruang } 23^{\circ} \pm 2^{\circ} \mathrm{C} \\
\text { selama } 24 \text { jam }\end{array}$ & - & $\mathrm{p}=0,001$ & $\mathrm{p}=0,0001$ \\
\hline $\begin{array}{c}\text { Microwave 600 } \\
\text { W selama 5 } \\
\text { menit }\end{array}$ & $\mathrm{p}=0,001$ & - & $\mathrm{p}=0,0001$ \\
\hline $\begin{array}{c}\text { Microwave 600 } \\
\text { W selama 10 } \\
\text { menit }\end{array}$ & $\mathrm{p}=0,0001$ & $\mathrm{p}=0,0001$ & - \\
\hline
\end{tabular}

Keterangan : * Signifikan $(\mathrm{p}<0,05)$

Nilai rerata perubahan dimensi pada kelompok A adalah $0,0112 \%$ dan standar deviasi 0,0009 . Nilai rerata perubahan dimensi pada kelompok B adalah $0,0077 \%$ dan standar deviasi 0,0009. Nilai rerata perubahan dimensi pada kelompok $\mathrm{C}$ adalah $0,0169 \%$ dan standar deviasi 0,0013 (Tabel 4).
Tabel 4. Nilai perubahan dimensi gips tipe IV model kerja gigi tiruan pada metode pengeringan dengan temperatur ruang $23^{\circ} \pm 2^{\circ} \mathrm{C}$ selama 24 jam dan microwave $600 \mathrm{~W}$ selama 5 menit dan 10 menit

\begin{tabular}{|c|c|c|c|}
\hline \multirow{2}{*}{$\begin{array}{c}\text { No. } \\
\text { Sampel }\end{array}$} & \multicolumn{2}{|c|}{$\begin{array}{c}\text { Perubahan Dimensi Gips Tipe IV Model } \\
\text { Kerja Gigi Tiruan (\%) }\end{array}$} \\
\cline { 2 - 4 } & $\begin{array}{c}\text { Kelompok } \\
\text { A } \\
\text { (Temperatur } \\
\text { Ruang } \\
23^{\circ} \pm 2^{\circ} \text { Csela } \\
\text { ma }\end{array}$ & $\begin{array}{c}\text { Kelompok } \\
\text { B } \\
\text { (Microwave } \\
600 \mathrm{~W} \\
\text { selama } \\
5 \text { menit) }\end{array}$ & $\begin{array}{c}\text { Kelompok } \\
\text { C } \\
\text { (Microwave } \\
600 \mathrm{~W} \\
\text { selama } \\
10 \text { menit) }\end{array}$ \\
\hline 1 & 24 jam) & & \\
\hline 2 & 0,0112 & 0,0080 & 0,0172 \\
\hline 3 & 0,0120 & 0,0076 & $0,0152^{*}$ \\
\hline 4 & $0,0100^{*}$ & $0,0096^{* * *}$ & 0,0180 \\
\hline 5 & 0,0100 & $0,0068^{*}$ & 0,0180 \\
\hline 6 & 0,0112 & 0,0080 & 0,0172 \\
\hline 7 & 0,0116 & 0,0080 & 0,0152 \\
\hline 8 & $0,0132^{* *}$ & 0,0092 & 0,0164 \\
\hline 9 & 0,0120 & 0,0076 & 0,0164 \\
\hline 10 & 0,0116 & 0,0080 & $0,0193^{* *}$ \\
\hline & $\bar{X}=0,0112$ & $\bar{X}=0,0077$ & $\bar{X}=0,0169$ \\
& $\mathrm{SD}=0,0009$ & $\mathrm{SD}=0,0009$ & $\mathrm{SD}=0,0013$ \\
\hline
\end{tabular}

Keterangan : * Nilai terkecil ** Nilai terbesar

Hasil uji ANOVA satu arah menunjukkan bahwa adanya pengaruh yang signifikan pada metode pengeringan dengan temperatur ruang $23^{\circ} \pm 2^{\circ} \mathrm{C}$ selama 24 jam dan microwave $600 \mathrm{~W}$ selama 5 menit dan 10 menit terhadap perubahan dimensi gips tipe IV dengan nilai $\mathrm{p}=0,0001(\mathrm{p}<0,05)($ Tabel 5).

Tabel 5. Pengaruh metode pengeringan dengan temperatur ruang $23^{\circ} \pm 2^{\circ} \mathrm{C}$ selama 24 jam dan microwave $600 \mathrm{~W}$ selama 5 menit dan 10 menit terhadap perubahan dimensi gips tipe IV model kerja gigi tiruan

\begin{tabular}{|c|c|c|c|}
\hline \multirow{2}{*}{ Kelompok } & \multicolumn{2}{|c|}{$\begin{array}{c}\text { Perubahan Dimensi } \\
\text { Gips Tipe IV Model } \\
\text { Kerja Gigi Tiruan (\%) }\end{array}$} & \multirow{2}{*}{$\mathrm{p}$} \\
\cline { 2 - 3 } & $\mathrm{n}$ & $\bar{X} \pm$ SD & \\
\hline $\begin{array}{c}\text { A } \\
\text { (Temperatur } \\
\text { Ruang } \\
23^{\circ} \pm 2^{\circ} \text { Cselam } \\
\text { a 24 jam) }\end{array}$ & 10 & $0,0112 \pm 0,0009$ & \\
\hline $\begin{array}{c}\text { B (Microwave } \\
600 \text { W selama } \\
5 \text { menit) }\end{array}$ & 10 & $0,0077 \pm 0,0009$ & \multirow{2}{*}{$\begin{array}{c} \\
\text { C (Microwave }=0,0001 \\
600 \text { W selama } \\
10 \text { menit) }\end{array}$} \\
\hline
\end{tabular}

Keterangan : * Signifikan $(\mathrm{p}<0,05)$

Untuk mengetahui perbedaan pengaruh antara kelompok temperatur ruang $23^{\circ} \pm 2^{\circ} \mathrm{C}$ selama 24 jam (kelompok A) dengan microwave $600 \mathrm{~W}$ selama 5 menit 
(kelompok B) dan microwave $600 \mathrm{~W}$ selama 10 menit (kelompok C) terhadap perubahan dimensi gips tipe IV model kerja gigi tiruan, dilakukan dengan uji LSD. Hasil uji LSD terdapat perbedaan kekuatan kompresi yang signifikan antara kelompok A dengan B, kelompok A dengan kelompok $\mathrm{C}$ dan kelompok $\mathrm{B}$ dengan kelompok $\mathrm{C}$ (Tabel 6).

Tabel 6.Perbedaan pengaruh metode pengeringan dengan temperatur ruang $23^{\circ} \pm 2^{\circ} \mathrm{C}$ selama 24 jam dan microwave $600 \mathrm{~W}$ selama 5 menit dan 10 menit terhadap perubahan dimensi gips tipe IV model kerja gigi tiruan

\begin{tabular}{|c|c|c|c|}
\hline $\begin{array}{c}\text { Kelompok gips } \\
\text { tipe IV model } \\
\text { kerja gigi tiruan }\end{array}$ & $\begin{array}{c}\text { Temperatur } \\
\text { ruang } \\
23^{\circ} \pm 2^{\circ} \mathrm{Csela} \\
\text { ma } \\
24 \mathrm{jam}\end{array}$ & $\begin{array}{c}\text { Microwave } \\
600 \mathrm{~W} \\
\text { selama } \\
5 \text { menit }\end{array}$ & $\begin{array}{c}\text { Microwave } \\
600 \mathrm{~W} \\
\text { selama } \\
10 \text { menit }\end{array}$ \\
\hline $\begin{array}{c}\text { Temperatur } \\
\text { ruang } 23^{\circ} \pm 2^{\circ} \mathrm{C} \\
\text { selama } 24 \text { jam }\end{array}$ & - & $\mathrm{p}=0,0001$ & $\mathrm{p}=0,0001$ \\
\hline $\begin{array}{c}\text { Microwave 600 } \\
\text { W selama 5 } \\
\text { menit }\end{array}$ & $\mathrm{p}=0,0001$ & - & $\mathrm{p}=0,0001$ \\
\hline $\begin{array}{c}\text { Microwave 600 } \\
\text { W selama 10 } \\
\text { menit }\end{array}$ & $\mathrm{p}=0,0001$ & $\mathrm{p}=0,0001$ & - \\
\hline
\end{tabular}

Keterangan : * Signifikan $(\mathrm{p}<0,05)$

\section{PEMBAHASAN}

Nilai kekuatan kompresi dan perubahan dimensi yang bervariasi dalam satu kelompok dapat disebabkan oleh beberapa faktor diantaranya adalah proses pembuatan sampel untuk setiap kelompok yang tidak dapat dilakukan sekaligus dalam waktu yang bersamaan. Teknik pengadukan yang dilakukan secara manual yang menyebabkan kecepatan pengadukannya tidak dapat dikendalikan dengan baik juga dapat memengaruhi variasi nilai kekuatan kompresi dan perubahan dimensi sampel gips tipe IV tersebut. Kemungkinan juga terjadinya poreus di dalam sampel gips tipe IV yang tidak dapat terlihat sehingga dapat menurunkan kekuatan kompresi. Faktor lain juga seperti temperatur dan kelembaban udara yang sulit dikontol secara sempurna dapat memengaruhi terjadinya ekspansi gips seiring berjalannya waktu yang berlangsung terus menerus hingga mencapai 5 hari. Selain itu, mekanisme pengeringan gips tipe IV pada metode pengeringan dengan temperatur ruang $23^{\circ} \pm 2^{\circ} \mathrm{C}$ selama 24 jam dengan pengeringan microwave $600 \mathrm{~W}$ selama 5 menit dan 10 menit juga berbeda, sehingga dapat menyebabkan variasi nilai kekuatan kompresi dan perubahan dimensi. ${ }^{9}$

Pengeringan dengan temperatur ruang hanya menyerap sisa kadar air pada bagian permukaan model kerja saja dan masih memiliki sisa kadar air yang dapat menurunkan kekuatan kompresi. Adanya sisa air yang terperangkap mengakibatkan kristal gips akan merenggang yang menyebabkan kohesi antara air dengan gips akan rendah sehingga mengakibatkan kekuatan kompresi juga rendah. Hasil akhir pengeringan gips tipe IV dengan temperatur ruang mengakibatkan bentuk kristal semakin besar, jumlah dan jarak antar kristal semakin besar dan menjadi kurang padat sehingga dapat menurunkan kekuatan kompresi. ${ }^{10}$ Berbeda dengan pengeringan microwave yang dikenal sebagai pemanasan dielektrik yang memiliki beberapa komponen utama salah satunya magnetron, yang merupakan sejenis tabung hampa penghasil gelombang mikro. Ketika gelombang mikro berinteraksi dengan molekul air yang terdapat pada bahan gips yang akan dikeringkan, molekul air akan menyerap energi elekromagnetik dengan mekanisme polarisasi yang disebabkan oleh medan listrik.Gelombang mikro akan memutar molekul-molekul air sampai molekul tersebut saling bertubrukan satu sama lain lalu akan menghasilkan panas, dan panas tersebut akan menyerap kadar air secara merata dengan waktu yang relatif singkat. Hasil akhir pengeringan dengan microwave dapat menghasilkan penyerapan air yang merata, pertumbuhan dihidrat semakin meningkat, bentuk partikel lebih padat, jumlah pori air semakin sedikit dan jarak antar kristal lebih besar sehingga mengakibatkan kekuatan kompresi semakin meningkat dibanding dengan pengeringan temperatur ruang ${ }^{10,11}$ Kandungan air yang masih tersisa dalam bahan gips juga merupakan faktor yang akan memengaruhi nilai perubahan dimensi. ${ }^{12}$ Pengeringan dengan temperatur ruang pada ekspansi gips akan berlangsung terus menerus selama 5 hari. Hal ini juga berhubungan dengan penyerapan sisa kadar air dengan pengeringan microwave, dengan hasil akhir dari pengeringan sisa air tersebut mengakibatkan kristal-kristal gips yang halus mengendap. Pengeringanmicrowave600 W selama 5 menitdengan adanya sisa air yang terperangkap dalam kisi kristal dapat mengakibatkan ruang antar nukleus sedikit lebih besar dibanding pengeringan microwave $600 \mathrm{~W}$ selama 10 menit. Pengeringan dengan microwave $600 \mathrm{~W}$ selama 10 menit mengakibatkan menyusutnya kristal-kristal gips akibat tidak adanya air dalam gips tersebut, bentuk partikel lebih padat, jumlah pori air semakin sedikit dan jarak antar kristal semakin dekat yang mengakibatkan nukleus kristalisasi per unit volume semakin besarsehingga dorongan keluar dari inti kristal semakin besar yangmenyebabkan setting ekspansi gips menjadi besar juga. Berbeda dengan kekuatan kompresi. Pengeringan microwave menghasilkan jumlah inti kristal lebih banyak, jumlah ikatan kristal yang lebih besar dan terjadinya prorositas akibat terperangkapnya air semakin berkurang yang mengakibatkan kekuatan kompresi dengan pegeringan microwave lebih tinggi dibanding dengan pengeringan temperatur ruang.Berbeda dengan kekuatan kompresi. Pada kekuatan kompresi, terperangkapnya air memudahkan terjadinya porositas pada gips yang menyebabkan kohesi antara air dengan gips menjadi rendah sehingga kekuatan kompresi menjadi rendah. ${ }^{10,13,14}$

Hasil penelitian ini pada metode pengeringan dengan microwave $600 \mathrm{~W}$ selama 5 menit dapat diterima sebagai pengeringan alternatif pada gips tipe IV model kerja gigi tiruan yang baik. Aplikasi klinis dapat diterima bahwa pengeringan alternatif dengan microwave $600 \mathrm{~W}$ selama 5 menit dapat juga mengurangi waktu kerja dokter gigi dalam hal 
menunggu model kerja mengeras, pada saat pembuatan mahkota dan jembatan gigi tiruan sementara pasien.

\section{DAFTAR PUSTAKA}

1. Hatrick CD, Eakle WS, Bird WF. Dental Materials. Clinical applications for dental assistants and dental hyginists. $2^{\text {nd }}$ ed. Missouri: Saunders Elsevier, 2011: 176, 203-9.

2. McCabe JF, Walls AWG. Applied dental materials. $9^{\text {th }}$ ed. Oxford: Blackwell Munksgaard, 2008: 32-9.

3. Anusavice KJ, Shen C, Rawls HR. Phillips Science of dental materials. $12^{\text {th }}$ ed. Missouri: Mosby Elsevier, 2013: 182-93.

4. Silva MAB, Vitti RP, Consani S, Sinhoreti MAC, Mesquita MF, Consani R.LX. Linear dimensional change, compressive strength and detail reproduction in type $I V$ dental stone dried at room temperature and in a microwave oven. J Apl Oral Sci 2012; 20 (5): 588-93.

5. Sharma A, Shetty M, Hegde C, Shetty NS, Prasad DK. Comparative evaluation of dimensional accuracy and tensile strength of a type IV gypsum using microwave and air drying methods. J Indian Prosthodont Soc 2013; 13(4): 525-30.

6. Hasan RH, Mohammad KA. The effects of drying techniques on the compressive strength of gypsum products. Al-Rafidain Dent J 2013; 5(1): 63-8.

7. Ahmad AS. Evaluation of some properties of iraqi plaster by using some additives and microwave drying technique. MDJ 2015; 12(1): 39-52.
8. Sun J, Wang W, Yue Q. Review on microwavematter interaction fundamentals and efficient microwave-associated heating strategies. Materials 2016; 9(231): 1-25.

9. Chun WP, Kim S, Lee KW. Hot air-microwave combined drying characteristics of gypsum board. Palma. Balearic Island, Spain 2011: 1-5.

10. Aljubouri ZA, Al-Rawas AM. Physical properties and compressive strength of the technical plaster and local juss. Iraqi J Earth Sciences 2009; 9(2): 4958.

11. Malaviya N, Shrestha A. Comparative evaluation of surface detail changes and compressive strength of gypsum casts and dies after immersion in hypochlorite solution and microwave irradiation. An in vitro study. International Journal of Contemporary Medical Researh 2016; 3(6): 154751.

12. Khalaf HAR, Mohammed MR. Effect of disinfectant agents on certain Physical and Mechanical Properties of Type IV Dental Stone. J Bagh College Dentistry 2014; 26(1): 24-31.

13. Michalakis KX, Asar V, Kapsampeli V,Trikka PM, Pissiotis AL, Hirayama. Delayed linear dimensional changes of five high strength gypsum products used for the fabrication of definitive casts. J Prosthet Dent 2012; 108(3): 189-95.

14. Michalakis KX, Stratos A, Hirayama H, Pissiotis AL, Touloumi F. Delayed setting and hygroscopic linear expansion of three gypsum products used for cast articulation. J Prosthet Dent 2009; 102(5): 3138 . 